\title{
AUMENTO DA INCONTINÊNCIA URINÁRIA EM NONAGENÁRIOS E CENTENÁRIOS DURANTE 0 ISOLAMENTO SOCIAL DA COVID-19
}

Vivian Ulrich; Projeto de extensão Atenção Multiprofissional ao Longevo (AMPAL) do Instituto de Geriatria e Gerontologia da PUCRS; viviulrich@gmail.com

Renata Breda Martins; Projeto de extensão Atenção Multiprofissional ao Longevo (AMPAL) do Instituto de Geriatria e Gerontologia da PUCRS; nutri.renatamartins@gmail.com Ângelo José Gonçalves Bós; Escola de Medicina da PUCRS; angelo.bos@pucrs.br

- Escola de Medicina da PUCRS, Porto Alegre, Brasil; - Projeto de extensão Atenção Multiprofissional ao Longevo (AMPAL) do Instituto de Geriatria e Gerontologia da PUCRS, Porto Alegre, Brasil

\section{RESUMO}

Introdução: Em nonagenários e centenários a incontinência urinária (IU) é frequente e pode ocasionar em diversas perdas afetando diretamente a qualidade de vida. Entre os fatores de risco para a IU está a diminuição da mobilidade, que pode ser maior durante a pandemia da COVID-19. Objetivo: Investigar o possível aumento da IU em nonagenários e centenários durante o isolamento social relacionado à pandemia da COVID-19. Métodos: Estudo longitudinal e observacional onde foram entrevistados nonagenários e centenários residentes em Porto Alegre e participantes do Projeto Atenção Multiprofissional ao Longevo. O contato foi realizado via ligações telefônicas realizadas de março a agosto de 2020. Comparou-se a IU em avaliações anteriores em 2016 e/ou 2018. As variáveis investigadas foram gênero, faixa-etária, cor, estado conjugal, atividade física durante a pandemia, com quem reside e IU. Resultados: Foram 59 entrevistados, a maioria mu-

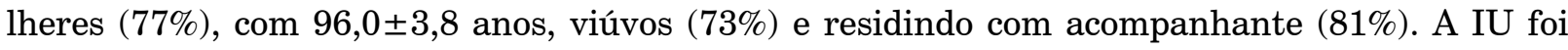
referida em $66 \%$ dos participantes nas duas semanas antes da entrevista (durante a COVID-19). Este percentual, antes da COVID-19, era de 55,9\%, um acréscimo de 10\%. O aumento percentual de IU foi maior entre os homens (21,4\%), com idade entre 95-99 anos (17,9\%), com companheiros $(16,7 \%)$, que moravam sozinhos $(18,2 \%)$ e os que diminuíram a atividade física durante a COVID-19 (17,4\%). Conclusão: A frequência de IU aumentou nos nonagenários e centenários avaliados, o aumento nos homens provavelmente esteja relacionado à diminuição da atividade física durante o período investigado.

Palavras-chaves: Incontinência urinária; Idoso de 80 Anos ou mais; Infecções por Coronavirus. 